\title{
O FLUXO DE MOEDAS ENTRE O RIO DA PRATA E O BRASIL — $(1800-1850)$.
}

\author{
ANTONIO E. MUNIZ BARRETO \\ da Faculdade de Ciências Econômicas e Administra- \\ tivas da Universidade de São Paulo.
}

\section{INTRODUÇÃO.}

O presente trabalho é uma tentativa de apresentar, dentro da evolução do comércio entre o Rio da Prata e o Brasil, uma quantificação do fluxo de moedas de prata castelhanas entre as duas áreas durante as primeiras décadas do século XIX.

Devido a sua localização geo-econômica, o Vicerreinado do Rio da Prata e, principalmente, a cidade portenha de Buenos Aires, passaram a acumular grande número de moedas de prata, na sua maior parte originárias do Perú.

Após a chegada da Corte Portuguesa em terras brasileiras, a já sentida escassez de meio circulante agravou-se e determinou grande procura das moedas de prata por parte dos luso-brasileiros, nos anos mencionados.

As primeiras tentativas de quantificação do fluxo monetário foram feitas em nosso trabalho Evolução Histórica do Comércio Argentino-Brasileiro 1800-1930.

O assunto é pouco conhecido, por isso nosso intuito, agora, é proporcionar uma análise do mesmo problema com maior pormenorização, acompanhada de uma bibliografia mais completa sobre o assunto, como guia sumário aos que desejarem aprofundar o problema.

Os dados quantitativos desse fluxo monetário foram obtidos, com as naturais restrições inerentes à qualidade dos registros, nos livros alfandegários do "Archivo General de la Nación", de Buenos Aires, em alguns Relatórios do Ministério da Fazenda do Brasil e, basicamente, 
na bibliografía existente sobre problemas monetários nos anos considerados .

Abordamos em primeiro lugar as principais características econômicas da região do Rio da Prata e do Brasil, nos anos abrangidos pelo estudo. Deste modo procuramos salientar, ainda que em traços sucintos, os comportamentos econômicos relacionados com o fluxo de moedas e, em especial, os problemas monetários existentes nas duas regiões.

Após estas considerações de carater mais geral, passamos a quantificar o fluxo de moedas.

Do material disponível foi possível obter algumas conclusões no que se refere ao comércio entre o Rio da Prata e o Brasil e o mecanismo básico do fluxo de moedas de prata entre as duas áreas consideradas .

\section{O PRATA, UMA SEGUNDA OPÇÃO.}

Depois de desenvolverem atividades econômicas distintas durante três séculos, a região do Rio da Prata e o Brasil das primeiras décadas do século XIX guardavam entre si marcantes e profundas diferenças econômico-sociais.

Com efeito, desde o seu descobrimento, o Brasil desempenhou o papel de fornecedor de produtos agrícolas tropicais ou de metais preciosos (no breve ciclo minerador) aos mercados europeus. Seja extraindo o pau-brasil, seja produzindo açucar, fumo e algodão, ou ainda explorando as minas auríferas, manteve seus traços fundamentais que, no dizer de Caio Prado Jr., são os de

"uma vasta empresa comercial, mais complexa que a antiga feitoria, mas sempre com o mesmo carater que ela, destinada a explorar os recursos naturais de um território virgem em proveito do comércio europeu" (1).

Ao lado disso, no início do século XIX, a colônia portuguesa apresentava pelo menos uma cidade de relativa importância populacional, política e comercial: o Rio de Janeiro, com aproximadamente 100.000 habitantes, abrigo da Corte de D. João VI - em decorrência dos acontecimentos europeus - cuja chegada, com apóio inglês, veio a consolidar essa importância.

(1). - PRADO JÚNIOR (Caio), Formação do Brasil Contemporâneo. Ed. Brasiliense Ltda., São Paulo, 1957, pág. 25. 
Não se pode fixar a mesma caracterização quando se trata da região do Rio da Prata. Suas condições ecológicas e seu clima temperado não lhe deram as mesmas oportunidades de participação no grande desenvolvimento comercial europeu, uma vez que esses fenômenos impossibilitavam a produção dos bens. que efetivamente interessavam ao comerciante do Velho Mundo.

A colonização do Prata surgiu vinculada ao desenvolvimento do Perú, centro dinâmico da América Espanhola, onde o ouro e a prata constituíam a base econômica. Esta vinculação se processava por meio de Buenos Aires, que a partir de seu surgimento passou a ser uma segunda opção na ligação das colônias sul-americanas com a Europa.

Se Buenos Aires tornou-se numa segunda opção de saida para a Europa, converteu-se tambem num centro de contrabando da prata peruana. E foi como comerciantes e contrabandistas no Prata que os portugueses conseguiram participar das vantagens econômicas oferecidas pelos metais preciosos (2). Aliás, o contrabando lusitano foi a forma com que o Rio da Prata escapou ao rígido monopólio imposto pela mentalidade mercantilista da Coroa espanhola (Buenos Aires acabou por se constituir num porto de entrada de portugueses e de saida da prata potosina) (3).

$\mathrm{O}$ auge desse comércio situa-se entre os anos de 1580 e 1640 quando, segundo Alice P. Canabrava, conheceu uma fase organizada, com apôio tanto em Buenos Aires, quanto no Brasil e na Europa (4) . E foi o seu desenvolvimento que obrigou as autoridades espanholas a organizar politicamente a região, surgindo assim, o Virreinato del Río de la Plata (1776), ao lado de uma legislação que aos poucos reconheceu um fluxo comercial que já existia há muito tempo de fato.

O hinterland da região - uma planície de grande extensão, formada de terras férteis - viu crescer um importante rebanho (basicamente bovino), que logo seria a base econômica de todo o Prata. Desenvolveu-se, desta forma, a dicotomia entre o litoral e o interior do Rio da Prata: o primeiro vinculado ao comércio internacional (legal ou de contrabando), o segundo, auto-suficiente e sem vinculações com o exterior. Esta dicotomia deu margem a constantes atritos, pre-

(2). - LAFUENTE MACHAIN (Ramiro), Los portugueses en Buenos Aires, Madrid, 1931.

(3). - ASSADOURIAN (Carlos S.), La Conquista in Historia Argentina. De la conquista a la independencia. Vol. 2. Paidós, Buenos Aires, 1972.

(4). - CANABRAVA (Alice Piffer), O Comércio português no Rio da Prata (1580-1640), São Paulo, 1944. 
valecendo, em geral, os interesses da cidade de Buenos Aires, ainda que esta fosse relativamente pequena em 1810 , quando sua população não passava de 50.000 habitantes (5), praticamente a metade da população do Rio de Janeiro.

\section{CARACTERÍSTICAS DO COMÉRCIO PRATA-BRASIL.}

Como consequência das diferenças ecológicas e climáticas, o comércio entre o Rio da Prata e o Brasil mostrava certa complementaridade: ambos eram produtores de matérias-primas e alimentos, destinados a paises de produção manufatureira.

O Prata entrava nesse comércio fornecendo produtos fundamentalmente ligados às suas atividades pecuárias. Exportava couros, carne-seca, sebo, banha, chifres e crinas, que eram vendidos ao Brasil, mas nem sempre consumidos em território brasileiro, já que, em muitos casos, reexportavam-se para outros paises, como a Inglaterra e Cuba.

O Brasil, por sua vez, fornecia açucar, erva-mate, farinha de mandioca, amido, café, doces, aguardente, fumo, arroz, madeiras, cascarilha, entre outros produtos. Mas teve papel relevante como fornecedor de produtos industrializados, comprados basicamente na Inglaterra: funcionando como centro reexportador, o Brasil oferecia grande variedade de tecidos e artigos de vestuário, tanto de luxo como rústicos (6), alem de ferramentas, máquinas simples e utensílios, remédios e drogas. É bem verdade que a Argentina chegou a vender essas mesmas mercadorias a paises como o Chile, Uruguai e Perú, mas numa escala bem menor que a brasileira.

Percebe-se, pois, que o Brasil participava desse comércio com uma pauta de produtos muito mais diversificada, enquanto a Argentina apresentava número escasso de mercadorias que, em geral, tinham a mesma origem: o seu rebanho bovino. Consequentemente, o fluxo comercial foi deficitário para os argentinos durante os primeiros cinquenta anos do século X I X.

(5). - CHIARAMONTE (José C. ), La Etapa Ilustrada 1750-1806 in Historia Argentina. De la conquista a la independencia. Vol. 2. Paidós, Buenos Aires, 1972.

(6). - MUNIZ BARRETO (Antônio E.), Evolução Histórica do Comércio argentino-brasileiro (1800-1930). Tese de Doutoramento. Faculdade Ciências Econômicas e Administrativas da Universidade de São Paulo, São Paulo, 1972, mimeo. 


\section{PROBLEMAS MONETARIOS DO RIO DE JANEIRO.}

Os problemas monetários conhecidos pela colônia portuguesa decorrentes de uma escassez crônica de moeda - podem ser conhecidos na obra de Azeredo Coutinho, Apreciação dos juízos emitidos sobre a moeda do Brasil e bem assim como sua casa de moeda (7).

Em fins do século XVIII, já circulavam na colônia boas quantidades de moedas cunhadas em Lisboa. Havia escassez de ouro e prata para a confecção de moedas, fato que se tornaria extremamente grave na primeira década do século passado.

"A difficuldade de obter oiro e prata para a amoedação originou várias providências, sendo das principaes o decreto de 31 de outubro de 1807 para a redução de parte da baixela da corôa, convidando tambem os particulares a seguirem tão patriótico exemplo, o edital do senado de 10 de novembro de 1810, publicando que na casa da moeda se acceitavam quaesquer peças de oiro ou prata, que pretendesse reduzir a dinheiro corrente. O edital de 31 de outubro de 1811 recomendou a observância das leis do reino contra a exportação do oiro ou prata amoedado ou em barra" (8).

A transferência da Corte de D. João VI para o Brasil, fazendo com que a capital da colônia passasse a ser. de fato, a capital do Império, acarretou toda uma série de problemas e modificações na circulação monetária.

De acordo com Valentim F. Bouças (9), a circulação monetária da época era composta, em dois terços, por moedas de ouro (umas denominadas peças portuguesas, outras denominadas peças coloniais por terem curso legal apenas no Brasil); menos de $1 / 3$ das moedas eram de prata, com diferentes relações (1:13 3/8 e 1:15 1/2). Havia ainda um certo número de moedas de cobre, e de moedas estrangeiras.

(7). - AZEREDO COUTINHO (Cândido de), Apreciação dos juízos emittidos sobre a moeda do Brazil e bem assim como sua casa de moeda, Rio de Janeiro, J. Villeneuve \& C., 1876.

(8). - TEIXEIRA DE ÄRAGÃO (A. C), Descripção Geral e Histórica das moedas cunhadas em nome dos reis regentes e governadores de Portugal, Tomo II, Lisboa. Imprensa Nacional, 1877, pág. 139.

(9). - BOUÇAS (Valentim F.), História da Dívida Externa, 2a. Edição, Edições Financeiras S. A., Rio de Janeiro, 1950, pág. 16. 
Amaro Cavalcanti (10) afirma que é difícil avaliar, exatamente, a quantidade de moeda metálica em circulação nesta época. Supõe, porem, que devido ao limitado movimento econômico da colônia, as espécies monetárias não deveriam ter sido abundantes. Diz ainda, que a Abertura dos Portos, ao intensificar o movimento comercial, agravou a escassez de moedas -, avaliando que a circulação monetária no ano de 1808 deveria estar por volta dos 9 ou 10.000 contos de réis, a maior parte dos quais em ouro $(*)$.

Dorival Teixeira Viera (11) nos mostra o quanto o sistema era complexo, havendo um mínimo de seis relações legais entre as moedas de prata e ouro (note-se que se consideram apenas as moedas legítimas) . Pires do Rio, por sua vez, analisa as moedas de então:

"O mil réis de D. João VI continha 2,159 gramas de ouro fino valendo 32,385 gramas de prata fina. O marco de prata, de toque legal, que continha 210 gramas de metal fino, valendo portanto $6 \$ 400$ moeda corrente" (12).

\section{A MOEDA DO RIO DA PRATA (1800-1820).}

Em razão de ser um dos pontos mais comerciais da América Espanhola, Buenos Aires conheceu importante fluxo monetário vindo do Perú e do Alto Perú, na segunda metade do século XVIII. Neste período cresceu a oposição Lima-Buenos Aires, com o predomínio dos interesses da cidade portenha. Esta, por sinal, subordinou aos seus

(10). - CAVALCANTI (Amaro), O Meio Circulante Nacional, $1^{\circ}$ Vol., Imprensa Nacional, Rio de Janeiro, 1893.

(*). - - Segundo Teixeira de Aragão, eram a sseguintes as moedas em circulação nos tempos de D. João VI:

Ouro: Dobra de quatro escudos ou peça; Dobra de dois escudos ou meia peça; Escudo ou dezesseis tostões; Meio escudo ou oito tostões; Quartinho; Cruzado Novo.

Prata: Cruzado Novo; Doze vintens; Seis vintens; Três vintens; Tostão; Meio Tostão.

Bronze: Dois vintens ou pataca; Trinta réis (ensaio); Vintem ensaio.

Cobre: Vintem; Dez réis: Cinco réis: Três réis.

(11). TEIXEIRA VIEIRA (Dorival), "Evolução do Sistema Monetário Brasileïro". Faculdade de Filosofia, Ciências e Letras, São Paulo, 1962, mimeo.

(12). - PIRES DO RIO (J.), A Moeda Brasileira, José Olympio, Rio de Janeiro, pág. 53. 
interesses tambem as províncias do interior argentino, e conseguiu aos poucos acumular grande número de moedas de prata e ouro (13).

Muitos autores atentam para o fato de que as restrições metropolitanas ao comércio possibilitaram a acumulação dessas moedas em Buenos Aires. Da mesma forma, quando se intensificou o contrabando e quando se liberou o comércio, já no século XIX, as moedas praticamente desapareceram.

As moedas circulantes nas colônias espanholas eram de prata, e cunhadas pela Casa da Moeda de Potosí. Nem sempre de boa qualidade - Potosí era famosa, entre outras coisas, pelos defeitos, muitas vezes intencionais, de suas peças (14), — as moedas podiam ser pesos dobles ou simples, que circulavam ao lado das defeituosas ou irregulares, conhecidas como macuquinas. Até o desenvolvimento do comércio (ou do contrabando), as compras de Buenos Aires eram feitas no interior; as moedas espanholas ou peruanas permaneciam dentro mesmo dos domínios coloniais espanhóis. De acordo com Levene, as peças de prata simples iam para o interior, ao passo que as dobles eram remetidas à Espanha que, nessa época, comprava couros através de Buenos Aires.

Nos fins do século XVIII, quando já estava estabelecido o Virreinato, as autoridades portenhas manifestaram sua preocupação com a saida da prata em direção ao Perú, chegando inclusive a proibir o envio do metal a Lima. Na verdade, porem, outros fatores é que contribuiriam para o processo de desaparecimento das moedas de prata que circulavam em grandes quantidades na região do Prata. Esses, com efeito, prendiam-se à série de medidas liberalizadoras do comércio com a Espanha, colônias estrangeiras e potências neutrais - culminada com a abertura de Buenos Aires ao comércio inglês em 1809 - e ao comércio ilegal ali praticado. É importante salientar que, logo nos primeiros anos do século XIX, começaram a rarear as moedas de prata de baixo valor, utilizadas como circulante na colônia e no mercado varejista.

Uma das formas encontradas para resolver o problema foi a subdivisão de moedas de maior valor em vários pedaços (tambem denominados macuquinas). Todavia, as autoridades manifestaram sua preocupação no sentido de evitar a circulação dessas moedas: empreenderam diversas tentativas de recolher as peças, a fim de envia-las a Po-

(13). - LEVENE (Ricardo), La Moneda Colonial del Plata, Ed. Coni Hermanos, Buenos Aires, 1916. (14). - LEVENE (Ricardo), La Moneda .... pág. 37. 
tosí, onde seriam recunhadas. Levene (15) informa que, apesar desses esforços, a moeda macuquina circulou até meados do século X IX.

As autoridades espanholas estabeleceram uma série de normas inclusive outorga de prêmios - para corrigir os fluxos das diferentes moedas:

Em 1771 uma disposição real, estabelecia que

"los salarios de toda clase de empleados y cargas que tuvieram las cajas de estos dominios, se pagariam en moneda de plata, debiéndose enviar a España, em doblones, los sobrantes de los productos totales" (16).

Assim, o ouro pode fluir para a Espanha.

O contrabando era em boa parte responsavel pela evasão de moedas, que passaram para a Inglaterra por meio dos portugueses, na segunda metade do século XVIII:

"las mercaderías inglesas enviadas desde Lisboa en las flotas de Río de Janeiro, y desde ahí transportadas por mar a la nueva colonia de Sacramento, adonde concurrían los españoles a comprar dichas mercaderías que eram pagadas en dinero que se retornaba a Lisboa en La flota de Río, la mayor parte del cual, puede decirse, entraba en Inglaterra. En los últimos años de la guerra con España (1762-1763) se demonstró la importancia de este comercio con las grandes cantidades de plata transportadas a Europa por las flotas del Brasil" (17).

Convém assinalar que a facilidade de transporte das moedas favorecia o seu contrabandeamento.

Mas os ágios e os prêmios oferecidos tambem provocaram a saida de peças de ouro da colônia, fazendo com que se concentrassem em Buenos Aires as moedas de prata - esse fato provocou protestos em Potosí, Tucuman, Córdoba e Mendoza (18) onde havia sérias preocupações em relação à escassez de moeda.

(15). - LEVENE (Ricardo), La Moneda .... pág. 47.

(16). - LEVENE (Ricardo), La Moneda .... pág. 48.

(17). - CHRISTELLOW (Allan), Gerat Britain and the Trades from Cadiz and Lisbon to Spanish America and Brazil, 1759-1783 in Villalobos R., Sergio, Comercio y contrabando en el Río de la Plata y Chile, Eudeba, Buenos Aires, 1965, pág. 20.

(18). - LEVENE (Ricardo), La Moneda ... pág. 51. 
Como resultado de tudo isso, pode-se inferir que a economia peruana, rica em metais preciosos, permitiu que Buenos Aires, com situação gegráfica privilegiada, conhecesse um fluxo comercial crescente a partir dos últimos anos do século X V I. E na medida em que a cidade portenha conseguia exportar seus produtos, acumulava moedas de todos os tipos. E, à medida que o comércio se intensificava seja o legal, seja o de contrabando - e as importações superavam as exportações, as peças metálicas foram desaparecendo dali (o processo, que se acelerou nos últimos anos do século XVIII, culminou com a eliminação quase total das restrições legais ao comércio exterior).

Por volta de 1820, circulavam já promissórias e certificados da Caja Nacional de Fundos de Sud America (19): foi aproximadamente nessa época que começou a circular em Buenos Aires o papel-moeda, substituindo as moedas metálicas insuficientes para atender às necessidades do movimento financeiro da ex-colônia espanhola.

\section{AS MOEDAS ESPANHOLAS NO BRASIL.}

Antes mesmo da vinda da Corte de D. João VI ao Rio de Janeiro, já circulavam moedas castelhanas no Brasil. Os problemas suscitados pelo curso no Brasil de moedas de procedência castelhana na última década do século XVIII foram sumariados por Severino Sombra. A rainha D. Maria I, no dia 22 de agosto de 1781,

"perguntou o tezoureiro mór do Real Erário, se poderia resultar prejuízo para a fazenda receber as patacas espanholas por 800 réis, como geralmente corriam. O provedor da casa da moeda informou em 15 de novembro, que das três variedades circulantes no mercado, as antigas de 7 1/2 oitavas e as columnárias, no seu peso e liga, eram ainda superiores a oito tostões, havendo vantagem por tal preço em se receberem, mesmo para se reduzirem a dinheiro nacional; enquanto as modernas, que tinham o busto do rei católico, sendo inferiores na prata, não convinham, pela perda que dava a sua afinação em 11 dinheiros".

"Em 3 de outubro de 1781 fez-se nova consulta fundada na representação do juiz de fora de Messejana, que atribuía a abundância dos pesos duros ao lucro que tiravam os espanhois na troca com as moedas de $6 \$ 400$, dando-os a 750 réis, e promovendo depois os especuladores o seu curso a 800 réis, o que deveria produzir no futuro a escassez do nosso dinheiro em ouro. O prove-

(19). - HANSEN (Emilio), La Moneda Argentina, Buenos Aires, 1916. 
dor da casa da moeda, não participando dos receios do juiz de fora, demonstrou a razão da importação da moeda hespanhola no reino, e a perda que resultava de se trocar em patacas a preço de 750 réis pelas peças de $6 \$ 400$, pois compradas a 800 réis, para se reduzirem a moeda portugueza, ainda a fazenda lucrava".

"Suscitaram-se nesta época muitas dúvidas com relação ao curso das patacas espanholas, até o governo resolver que se aceitassem, não sendo falsas ou cerceadas, a 800 réis cada uma, e que fossem reduzidas a dinheiro nacional, conforme a opinião do provedor e oficiais da casa da moeda" (20).

Exemplo deste fato consta na correspondência de Venâncio de Seixas, Provedor da Casa da Moeda da Bahia, à rainha D. Maria I, em 1799:

"... conviria aproveitar a oportunidade imitando a Casa da Moeda do Rio de Janeiro onde se trabalha muito na redução das patacas castelhanas, sendo da maior evidência que se as patacas castelhanas hão de girar, como giram, nestas colônias sem pagarem cousa alguma a V. Magestade, é muito melhor que girem depois de reduzidas à moeda provincial..." (21).

A preocupação com as moedas espanholas continuou após a chegada do Regente. Em certa medida, chegou mesmo a aumentar, já que o número de moedas cresceu consideravelmente com a intensificação do comércio com o Prata. Nessa ocasião, as principais moedas de prata em circulação eram de 640,320, 160, 80, 40 e 20 réis, denominadas, respectivamente, duas patacas, uma pataca, meia pataca, quatro vintens, dois vintens, e um vintem. artigo a:

O Alvará de $1^{\circ}$ de setembro de 1808 , dizia o seguinte, em seu

"... atendendo a precisão que há de moeda de prata na capitania de Minas Gerais fossem os pesos hespanhois marcados a punção com o cunho das armas reaes, affim de correrem na dita capitania com valor de 960 réis, que é o mesmo que valeriam" (22).

(20). -TEIXEIRA DE ARAGAO (A. C), Descripção Geral .... págs. 114 e 115 .

(21). - SOMBRA (Severino), História Monetária do Brasil Colonial, Rio de Janeiro, 1938, pág. 257.

(22). - CAVALCANTI (Amaro), O Meio Circulante .... pág. 8. 
O Alvará de 17 de outubro, por sua vez,

"estado verificado pelos ensaios da Casa da Moeda ser de 800 réis o valor relativo das patacas espanholas de prata", ordena que "tivessem estas o curso e fossem recebidas em todos os pagamentos e transações, e nas repartições públicas, por aquele valor...".

Este Alvará, comenta Cavalcanti, teria sido promulgado com o fim exclusivo

"de dar uma solução à grande dificuldade da enorme quantidade de patacas espanholas, introduzidas no Reino pelos exércitos ingleses, então aliados da causa portuguesa, os que eram pagos naquela moeda" (23).

Por causa dessa escassez de metal, o Regente mandou fundir muita prata estrangeira, principalmente as patacas castelhanas que, segundo Teixeira de Aragão, deram vultuosos lucros à Coroa.

"Expulsos de Portugal os franceses pela convenção de Cintra, a nova regência ordenou, em 14 de outubro de 1808, a compra de todas as patacas castelhanas, que se podessem obter a $6 \$ 800$ réis o marco, e que o provedor activasse a sua redução em moeda nacional. Outra portaria de 18 de setembro de 1810 torna a instar pela fabricação da moeda, devendo preferir-se a prata das barras e peças compradas pelo seu valor intrínseco, e na sua falta as patacas hespanholas, contanto que não escedesse o preço de 800 réis cada uma, que era por quanto corriam nos mercados" (24).

Alem das moedas espanholas legítimas, teriam circulado no Brasil "moedas espanholas" fabricadas na Inglaterra. O historiador Diego Luis Molinari cita o episódio do embaixador espanhol em Londres, Simon de Las Casas, que descobriu em Birmingham uma fábrica de falsas moedas castelhanas, com a tolerância governamental (para a fabricação, utilizavam-se "métodos perfeccionados") (25). A partir

(23). - CAVAlCANTI (Amaro), O Meio Circulante .... pág. 10.

(24). - TEIXEIRA DE ARAGÂO (A. C), Descripcão ....., păg. 143.

(25). - FUGIER "Napoleon et l'Espagne, 1799-1808", Paris, 1930, T I, pág. 25 in Molinari, Diego Luis "La Política Lusitana y el Río de la Plata" in Levene, Ricardo Historia de la Nación Argentina, vol. IV, pág. 399, El Ateneo, Buenos Aires, 1940. 
dai, pode-se inferir que nem toda a moeda castelhana circulante no Brasil era fruto do comércio com as colônias espanholas, mas produto do comércio inglês com as duas regiões, e do pagamento a seus soldados. Provavelmente haveria tambem algumas fabricadas em Birmingham!

De qualquer forma, a chegada das patacas castelhanas ajudou bastante aos portugueses na solução do problema da escassez monetária da colônia. Ao mesmo tempo, a autorização do comércio intercolonial, e a tentativa de autorização ao comércio entre Buenos Aires e as colônias estrangeiras pela Real Ordem (10-7-1796) trouxe flagrantes benefícios ao Brasil que, até então, podia valer-se apenas de formas ilegais de trocas.

As moedas do mundo hispânico eram carimbadas pelas Casas da Moeda do Rio de Janeiro, Bahia, Minas e São Paulo, Goiás e Mato Grosso. A partir de então, a grande preocupação das autoridades foi impedir a circulação clandestina das moedas e de ouro em pó, pelo interior do Brasil e, por causa disso, providenciou-se logo a recunhagem das peças metálicas estrangeiras. O Alvará de 8 de novembro de 1808 determinava

"o troco de ouro em pó nas casas de fundição e nas de permuta à razão de $371 / 2$ réis de ouro em pó, ou $1 \$ 200$ por oitava; cujo troco só se fará com a moeda para tal fim destinada e com cilhetes impressos dos valores de $1,2,4,8,12$, e 16 vintens de ouro; que em Minas não girassem mais os pesos espanhois não marcados nem mesmo como gênero de comércio e, finalmente, proibindo a entrada ou saida delas nos registros da capitania, onde os marcados correriam como moeda provincial" (26).

A série de mudanças e as políticas traçadas em relação aos pesos espanhois nos primeiros anos do século XIX, podem ser assim resumidas, de acordo com Kurt Prober:

Alvará de 17-10-1808 — estabelece o valor de 800 réis;

Provisão de 8-5-1809 — ordena o recebimento a 750 réis;

Aviso de 19-6-1809 — autoriza a compra de até 100.000 pesos para Goiás, Mato Grosso e São Paulo a 800 réis;

Portaria de 15-11-1810 — determina a compra, na Bahia, a 800 réis;

(26). - PADUA (Saturnino de), Moedas Brasileiras, 2a. edição, Rio de Janeiro, 1941, pág. 125. 
Portaria de 25-5-1811 — idêntica à portaria anterior; Aviso de 22-9-1812 - manda comprar pesos a 820 réis;

Portaria de 3-12-1812 - fixa o valor dos pesos a 800 réis; Aviso de 4-8-1814 — ordena a compra de 840 réis;

Provisão de 14-12-1815 - manda comprar, em Pernambuco e Maranhão, os pesos pelo preço corrente do Mercado;

Portaria de 13-9-1819 - autoriza as Juntas do Norte a comprar pesos até o valor de 820 réis;

Decisão de $8-5-1820$ - $\left(\mathrm{n}^{\circ}\right.$ 30) autoriza o governador do Piauí a receber os pesos, em pagamento pelo preço de 800 réis, se este fosse o preço da praça;

Decisão de 8-8-1820 - ( (n ${ }^{\circ}$ 43) manda que os pesos sejam recebidos nas províncias pelos preços correntes, sendo o limite máximo o valor de 820 réis (27).

O movimento comercial entre as duas regiões, por sua vez, processava-se desta forma, segundo análise de Cuccorese e Pannetieri:

"... le envia al Brasil: lana, harina, astas, jabón, sebo y
carne".

"Se recibe del Brasil: negros, algodón, añil, especiarias, cera, miel, pipas de aguardiente y azúcar. Este ensayo (referem-se aqui à tentativa do desenvolvimento do comércio com as colônias estrangeiras) acentúa la acción del contrabando. Al Brasil le interesa la moneda metálica; y no los frutos rioplatenses. Los barcos que parten de Buenos Aires llevan metálico, compran mercaderías en puertos brasileños y las venden, a su regreso, en Montevideo y Buenos Aires. Obtienen muy buenas utilidades" (28).

As autoridades portenhas tinham boas razões para se alarmar com o esvaziamento monetário do Prata. De um lado, a guerra entre espanhois e ingleses (1796-1802) possibilitou aos portugueses maior expansão em seus territórios, nos quais obtinham importantes lucros, de acordo com o que nos informa D. L. Molinari (29). Acentuou-se, com isso, a procura de moedas de prata, as mais utilizadas rio comércio legal ou ilegal.

(27). - PROBER (Kurt), Moedas falsas e falsificadas no Brasil, Rio de Janeiro, 1946, pág. 23.

(28). - CUCCORESE (Horacio Juan) e PANETTIERI (José), Argentina. Manual de História Económica y Social, Tomo I, Macchi, Buenos Aires, 1971, pág. 148.

(29). - MOLINARI (Diego Luis), "La Política Lusitana y el Río de la Plata" in Levene, Ricardo Historia de la Nación Argetina, vol. IV. El Ateneo, Buenos Aires, 1940. 
De outro lado, as moedas de ouro eram, praticamente, monopolizadas pela Metrópole. Já em 1791, as necessidades da Coroa espanhola eram tais, que se promulgou uma disposição determinando o pagamento de salários (a todo tipo de empregados) e de outras despesas, em moedas de prata.

"Esta circunstancia determinaba una valorización extraordinária de las monedas de oro. Se hacía verdadera especulación com ellas, notandose visibles variaciones en su precio" (30).

E com efeito, essas diferentes procuras do ouro e da prata acarretavam uma contínua variação na relação entre as duas espécies metálicas .

Dessa forma, os pesos dobles transferiam-se para o exterior, e os pesos simples para o interior (como pagamento dos artigos que o hinterland fornecia para o consumo de Buenos Aires). Essa evasão obrigou as autoridades portenhas a tomarem certas medidas. Uma delas, levava em conta o exemplo de uma proposta feita ao Cabildo em 1773, pedindo que as compras feitas por Buenos Aires, de

"vinhos, aguardente, tabaco e demais frutos",

fossem pagas com produtos da própria cidade. Trata-se da imposição feita em 1809 - na ocasião, Buenos Aires era declarada porto livre ao comércio britânico - segundo a qual, as embarcaçães que chegassem para vender suas mercadorias, deveriam levar de volta $2 / 3$ do valor em produtos locais, para evitar assim, a saida de moedas (31).

Mas, se a evasão de peças metálicas criou problemas aos portenhos, não deixou de cria-los tambem para as autoridades do Brasil.

É bem verdade que o comércio com o Prata trouxe grandes lucros aos comerciantes e à Coroa. Capistrano de Abreu mostra, neste trecho, a essência do comércio da época, ressaltando a importância que as moedas de prata tiveram para os comerciantes brasileiros:

"Na Bahia, por volta de 1803, cerca de quarenta navios de duzentos e cincoenta toneladas cada um empregavam-se no comércio do xarque do Rio Grande, que mal completavam a viagem

(30). - LEVENE (Ricardo), La Revolución de Mayo y Mariano Moreno, Tomo I, Facultad de Derecho y Ciencias Sociales, Buenos Aires, 1920, pág. 201.

(31). - LEVENE (Ricardo), La Revolución de Mayo .... pág. 201. 
dentro de dois anos. Levavam da Bahía, aguardente, assucar, louça, mercadorias européias, principalmente inglêzas e allemãs, que passavam por prata de contrabando em Maldonado e Montevideo. Durante este tempo as tripulações empregavam-se em carregar couro e carne seca" (32).

Até novembro de 1808, as patacas espanholas eram carimbadas com o valor de 800 réis, pasando depois a valer 960 réis. Segundo o que ordenava o Alvará de 9 de novembro de 1808, esas moedas deveriam ser distribuidas

"pelas 4 casas de Fundição de Minas Gerais para a carimbagem dos pesos espanhois, de 24 pares de cunhos com as Armas Reaes",

mandando ainda

"seja feita a remessa de 70.137 pesos que depois de marcados deveriam ser empregados no resgate de outros cuja circulação é proibida" (33).

Ao lado dessa carimbarem, que ofereceu muitos lucros à Coroa, já que 750 réis passaram a valer 960 (28\%, portanto), apareceu o fenômeno da falsificação dos carimbos, assim analisado por Azeredo Coutinho:

"Ordenara o alvará que se fabricassem moedas de 960 réis; o que se fez? Mandou-se por um carimbo sobre os pesos ou patacas espanholas, e emiti-las com o valor acima. Ora, como a imitação de tais moedas só dependesse de obter-se um carimbo semelhante ao que se empregava nas repartições monetárias do Brasil e de marcar com eles os pesos que custavam 750 réis, para ter um lucro de $210 \mathrm{em}$ cada um; consta que existia nessa época um navio, o qual ia do Rio de Janeiro ao Rio da Prata comprar pesos que carimbados durante a viagem, eram, nesta cidade, emitidos com o valor de 960 réis. Parece que parte desta manobra foi conhecida, e por isto mandou-se acabar com o carimbo e começar a recunhagem" (34).

(32). - ABREU (Capistrano de), Capítulos de História Colonial (1500-1800), Leuzinger, Rio de Janeiro, 1928, pag. 288.

(33). -SOMBRA (Severino), História Monetária .... pág. 279.

(34). - AZEREDO (Coutinho), "Estudo sobre a moeda de cobre e a subdisiária do Brasil", Rio de Janeiro, 1968, in Cavalcanti, Amaro, O Meio Circulante .... pág. 11. 
A carimbagem de moeda foi criticada pelos brasileiros interessados nos problemas monetários: afirmavam que a nova relação monetária era a responsavel pelo desaparecimento da moeda mais forte, segundo a lei de Gresham. Amaro Cavalcanti, no entanto, quantificou a recunhagem das moedas, defendendo a posição do governo português (considerava que não houvera, na realidade, tanto lucro): entre 1808 e 1822 foram recunhados 12.669 .785 pesos de prata, com um custo total de 10.253:994\$511, a um preço médio de 815,22 réis cada um (35).

Teixeira de Aragão, por outro lado, apresenta custos e lucros de forma diferente, coincidindo, porem, com a conclusão de Cavalcanti, quanto as vantagens que isso teria representado à Coroa portuguesa. Ele quantificou o processo chegando à conclusão que o lucro a favor da fazenda foi de $945 \$ 470$ réis.

"Além deste lucro a dinheiro, que variava conforme o custo das patacas, havia a conveniência de empregar os operários da casa da moeda e a de augmentar no mercado a moeda nacional" (36).

É interessante salientar o fato de que as patacas castelhanas não circulavam apenas no Brasil, mas tambem em outros territórios coloniais portugueses, nas Açores e na Madeira.

A recunhagem de moedas espanholas chamou a atenção de observadores como Horace Say e Kurt Prober. O primeiro, embora equivocado quanto à data do início da recunhagem cita o fato em seus comentários sobre a moeda colonial brasileira:

"Le governement de Jean VI (alors régent) avait commencé en 1811 par alterer la monnaie d'argent en infligeant à la piastre espagnole une empreinte nouvelle, qui portait la valeur nomínale de la pièce à vingt pour cent an dessus de sa valeur intrinsèque" (37). ma que

O segundo, em seu estudo acerca da moeda falsa no Brasil, afir-

(35). - CAVALCANTI (Amaro), O Meio Circulante ..., pág. 16.

(36). - TEIXEIRA DE ARAGÃO (A. C), Descripção ..... pág. 143.

(37). - S A Y (Horace), Histoire des Relations Commerciales entre la France et le Brésil, et considerations génerales sur les monnaies, les changes, les Banques et le commerce Exterieur, Chez Wuillaumin, 1849, pág. 87. 
"só os 13.156.350 de patacões recunhados na Casa da Moeda do Rio de Janeiro, entre 1810 e 1822, deram ao Real Erário o lucro de 1.334:304\$100" (38).

O lucro obtido na recunhagem continuou até 1822 , de acordo com Teixeira de Aragão. Nessa ocasião, a escassez de moeda espanhola impediu a continuação dessa política, fato que, aliás, coincide com a intensificação do comércio no Rio da Prata, principal fornecedor das patacas - isso veio a provocar alguns problemas de ordem comercial, e uma alta na taxa de juros.

Os comentários e observações transcritos mostram a importância das patacas espanholas na atenuação da excassez monetária do Brasil colonial. Os quadros seguintes permitirão o exame da quantificação legal do material existente no Archivo de la Nación Argentina:

\section{QUADRO $\mathrm{N}^{0} \mathrm{I}$.}

\section{EXPORTAÇÕES DE MOEDAS PARA O BRASIL.}

$\begin{array}{lrccccc}\text { Ano } & \text { Pesos } & \text { Pesos } & \text { Pesos sem } & \text { Marcos } & \text { Ouro } \\ 1800 & 120.028 & & & & & \\ 1801 & 121.320 & 31.456 & & & & \\ 1802 & 58.787 & & & & \\ 1810 & 7.350 & & & 6 & \\ 1813 & 78.415 & 199.916 & & & \\ 1814 & 81.313 & 305.371 & & & & \\ 1815 & 55.393 & 96.715 & & & & \\ 1816 & 4.000 & & & & & \\ 1817 & 500 & & & & & \\ 1818 / 22 & & 100.155 & & & & \\ 1836 & 1.283 & 540 & 3.696 & 46.460 & & \\ 1837 & 7: 126 & 7.475 & 7.804 & 4.505 & & 2.425\end{array}$

FONTE: Muniz Barreto (Antônio E.), Evolução Histórica do Comércio Argentino-Brasileiro (1800-1930). Tese de Doutoramento, São Paulo, 1972, mimeo.

A seguir vejamos os dados obtidos para o fluxo de moedas no sentido inverso.

(38). - PROBER (Kurt), Moedas falsas ... pág. 23. 
QUADRO $\mathrm{N}^{\circ}$ II.

EXPORTAÇÕES DE MOEDAS PARA A ARGENTINA.

\begin{tabular}{|c|c|c|c|c|c|c|c|}
\hline Ano & Pesos & $\begin{array}{l}\text { Pesos } \\
\text { Fortes }\end{array}$ & $\begin{array}{l}\text { Pesos Pra- } \\
\text { ta Selada }\end{array}$ & Patacões & $\begin{array}{r}\text { Marcos } \\
\text { (Ouro) }\end{array}$ & $\begin{array}{r}\text { Onças } \\
\text { Ouro }\end{array}$ & $\begin{array}{l}\text { Oitavas } \\
\text { (Ouro) }\end{array}$ \\
\hline $\begin{array}{ll}1810 & \\
1811 & 21\end{array}$ & 1.909 & 14.668 & & & & & \\
\hline 1813 & & 59.160 & & & 4 & & \\
\hline 1814 & & 29.355 & & & & & \\
\hline 1815 & & 1.288 & & & & & \\
\hline $1818 / 21$ & & & 20.000 & 3.500 & & 37 & 3 \\
\hline 1835 & 660 & & · & & & & \\
\hline FONTE: & $\begin{array}{r}\mathrm{M} \\
\text { gent } \\
197\end{array}$ & $\begin{array}{l}\text { Barreto } \\
\text { Brasileir } \\
\text { imeo }\end{array}$ & $\begin{array}{c}\text { (Antônio } \\
o(1800-1930\end{array}$ & $\begin{array}{l}\text { E.), Evol } \\
\text { ). Tese }\end{array}$ & $\begin{array}{c}\text { ao Históri } \\
\text { Doutor }\end{array}$ & $\begin{array}{l}\text { do } C \\
\text { ento, }\end{array}$ & $\begin{array}{l}\text { lércio Ar- } \\
\text { o Paulo, }\end{array}$ \\
\hline
\end{tabular}

Convem ressaltar que os dois quadros não consideram as transações ilegais, alem de se apresentarem de forma incompleta, já que não estão presentes vários dados. De qualquer maneira, fica evidente que o fluxo de moedas era deficitário para a Argentina: embora haja remessas de moedas no sentido Brasil-Argentina, estas não foram na mesma magnitude observada no sentido inverso.

Saliente-se ainda, que as moedas de ouro não aparecem nos anos considerados, surgindo somente depois da década dos trinta.

Se atentarmos agora para outro quadro $\left(n^{\circ}\right.$ III), veremos as características gerais das exportações totais de Buenos Aires nos anos de $1822,1825,1829$ e 1837.

Podemos observar que o comportamento das moedas segue um curso muito semelhante ao verificado no Brasil: grande número delas saem ainda nos primeiros anos da década de 20 (aproximadamente $30 \%$ nos anos de 1822 e 1825), número este que decresce no fim da década, para cair mais acentuadamente na década seguinte. A participação do ouro, porem, mostra-se mais estavel, com uma ligeira tendência ao aumento (nos quatro anos observados).

Aparentemente, esse fluxo de moedas permaneceu assim durante toda a metade do século passado: a Argentina teria que compensar seu déficit comercial com o Brasil, exportando moedas. O fato aparece claramente em dados obtidos nos Relatórios do Ministério da Fazenda, para o período de 1846 a 1855 : 
QUADRO $\mathrm{N}^{\mathrm{o}}$ III.

EXPORTAÇÕES DE BUENOS AIRES.

\begin{tabular}{|c|c|c|c|c|}
\hline & 1822 & 1825 & 1829 & 1837 \\
\hline & $\begin{array}{l}\text { Valor pe- } \\
\text { sos prata }\end{array}$ & $\begin{array}{l}\text { Valor pe- } \\
\text { sos prata }\end{array}$ & $\begin{array}{l}\text { Valor pe- } \\
\text { sos prata }\end{array}$ & $\begin{array}{l}\text { Valor pe- } \\
\text { sos prata }\end{array}$ \\
\hline Pesos Prata & 474.633 & 1.272 .745 & 189.581 & 258.743 \\
\hline Marcos Prata & 677.520 & 89.751 & 101.592 & 39.048 \\
\hline Ouro Onças & 204.340 & 180.625 & 418.115 & 373.983 \\
\hline Ouro barras & $\overline{ }$ & 6.000 & 13.667 & 6.154 \\
\hline Cobre & 2.321 & 2.800 & & \\
\hline Couros vacuns & 2.361 .488 & 2.621 .020 & 3.419 .196 & 3.294 .540 \\
\hline Couros equinos & 421.566 & 339.703 & 96.844 & 38.046 \\
\hline Carne salgada & 350.652 & 521.444 & 329.638 & 446.192 \\
\hline Chifres & 47.110 & 93.228 & 90.000 & 26.070 \\
\hline Crinas & 114.411 & 134.028 & 110.046 & 211.116 \\
\hline Läa & 33.417 & سשســ & 30.334 & 329.412 \\
\hline Pele chinchila & 36.308 & $\longrightarrow$ & 33.125 & 13.268 \\
\hline Pele Lontra & 29.742 & 178.350 & 179.268 & 129.632 \\
\hline Sebo & 124.800 & 18.250 & 65.271 & 150.373 \\
\hline Quina & 2.912 & 2.939 & —ــ & \\
\hline Algodão & & 5.000 & 1.936 & 480 \\
\hline Couros ovelha & & & & 140.470 \\
\hline Farinha & - & ( & $\longrightarrow$ & 56.268 \\
\hline Trigo & & & - & 14.525 \\
\hline Diversos & 118.708 & 84.117 & 121.387 & 108.818 \\
\hline Valor metais & 1.358 .814 & 1.551 .921 & 722.955 & 677.922 \\
\hline Frutos do pais & 3.641 .186 & 3.998 .079 & 4.477 .045 & 4.959 .216 \\
\hline Total & 5.000 .000 & 5.550 .000 & 5.550 .000 & 5.637 .138 \\
\hline
\end{tabular}

FONTE: Parish (Woodbine), Buenos Airès y las Provincias del Rio de la Plata desde su descubrimento y conquista por los Españoles. Hachette, Buenos Aires, 1958, pág. 511. 


\section{QUADRO $\mathrm{N}^{\circ}$ IV. \\ EXPORTAÇÕES DE MOEDA DOS ESTADOS DO RIO DA PRATA PARA O BRASIL.}

$\begin{array}{ccc} & \text { VALOR EM } & \% \text { DA EXPORTAÇÃO } \\ \text { ANO } & \text { MIL RÉIS } & \text { TOTAL DO PRATA } \\ 1846 / 47 & 406055 & 41,90 \\ 1847 / 48 & 772761 & 59,60 \\ 1848 / 49 & 457035 & 24,40 \\ 1849 / 50 & 315721 & 24,70 \\ 1850 / 51 & 293541 & 18,00 \\ 1851 / 52 & 268220 & 13,80 \\ 1852 / 53 & 421456 & 16,40 \\ 1853 / 54 & 216524 & 49,20 \\ 1854 / 55 & 2123074 & 50,30\end{array}$

FONTE: Muniz Barreto (Antônio E.), Evolução Histórica do Comércio Argentino-Brasileiro (1800-1930). Tese de Doutoramento, São Paulo, 1972, mimeo.

O quadro acima indica as exportações de Moeda do Estado Oriental e da Confederação Argentina, em conjunto, calculadas por anos que abrangem o segundo semestre de cada ano somado ao primeiro semestre do ano seguinte. A estrutura produtiva dos dois paises exportadores era muito semelhante: ambas se baseavam em produtos derivados de rebanho bovino, como couros, sebo, carne-seca, etc.

Observa-se uma participação muito alta de moedas nos dois primeiros anos considerados, que cai nos quatro anos seguintes, para voltar a aumentar nos dois últimos anos em que há disponibilidade de dados. A explicação que, aparentemente justificaria essa queda: os conflitos armados que culminaram com a deposição de D. Juan Manuel de Rosas do governo argentino.

A tendência deficitária para a Argentina continuaria até a década dos oitenta, quando passa a incluir em sua pauta de exportação, o trigo e a farinha de trigo. Aí então, a situação se inverte, e o comércio torna-se deficitário para o Brasil. Mas, até que essa nova tendência se fixasse, a situação ainda provocaca preocupações, como as do cônsul brasileiro em Buenos Aires, João Carlos Pereira Pinto, que analisou a conjuntura da década de 60 , e que chegou a se alarmar com o déficit argentino (39). Até que mudasse a configuração do inter-

(39). - MUNIZ BARRETO (Antônio Emílio), Evolução Histórica do Comércio Argentino-Biasileiro 1800-1930, Tese de Doutoramento, São Paulo, 1972, mimeo. 
câmbio entre o Brasil e o Prata, continuavam as transferências de moedas, se bem que através de organizações financeiras mais complexas, onde as moedas não mais desempenhavam um papel tão importante e nem eram recarimbadas, como acontecia nos primeiros anos do século XIX.

Em resumo, devido à sua situação geográfica, seu clima e suas condições ecológicas, a Argentina não pode participar, na mesma medida em que o Brasil participou, do grande desenvolvimento comercial europeu, ampliado a partir do século X V I . Em consequência disso, a região da atual República Argentina não foi outra coisa que uma segunda opção para a Europa, já que a primeira materializava-se no Perú, centro dinâmico que, desde os primeiros tempos da colonização ofereceu enorme quantidade de metais preciosos aos europeus.

Com restrições de tipo mercantilista, tentou-se impedir o desenvolvimento comercial da região do Prata. As restrições, no entanto, não conseguiram evitar o comércio baseado no contrabando. Os impedimentos legais, somados à decadência da mineração e da economia do Perú, possibilitaram a acumulação de moedas de prata na cidade portenha de Buenos Aires.

A escassez de moedas no Brasil - problemas que se agravou com a chegada da Corte, e com a Abertura dos Portos - foi a principal razão pela qual os portugueses se interessaram em adquirir moedas castelhanas . Estas possibilitaram um certo alívio ao meio circulante brasileiro, o qual não se adequava às necessidades monetárias - cada vez maiores - decorrentes da intensificação do comércio.

Houve um fluxo de moedas de prata em direção ao Brasil por meio, tanto de um comércio legal, quanto do contrabando. A atividade dos contrabandistas foi particularmente intensa durante as primeiras décadas do século X IX .

O intercâmbio entre a Argentina e o Brasil foi deficitário para o primeiro país até a década dos oitenta do século pasado; ou seja, até que o trigo e a farinha de trigo ganhassem importância na pauta de exportações dos argentinos. Foi por causa do déficit apontado, que o Prata teve que abrir mão de suas moedas. 